\title{
O diário de Carolina Maria de Jesus. Uma brasileira marginalizada
}

\author{
El diario de Carolina Maria de Jesus. \\ Una brasileña marginada
}

\section{The diary of Carolina Maria de Jesus. A marginalized Brazilian}

\author{
Regina Simon da Silva \\ David Raphael Araujo da Fé \\ Universidade Federal do Rio Grande do Norte (UFRN). \\ Brasil \\ Recibido: 3 de febrero de 2017 \\ Aceptado: 15 de febrero de 2017
}

\section{Resumo}

Neste texto, analisamos o livro Quarto de despejo: diário de uma favelada (2015), publicado nos anos sessenta, pela então desconhecida Carolina Maria de Jesus. Escrito sob o formato de diário, Carolina retrata a visão interna de uma nova realidade que consternaria a população brasileira até os dias atuais: a favela. Em seus escritos, a autora trouxe

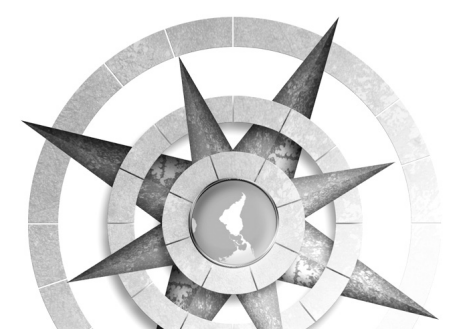

consigo uma série de estigmas que marcaram, pejorativamente, o seu registro: era mulher, negra, pobre e semianalfabeta. Por isso, suas obras dividem opiniões acerca do seu valor literário. Este artigo objetiva analisar seu primeiro livro, evocando aspectos autobiográficos e memorialísticos em relação ao seu tempo e espaço.

Palavras-chave: Literatura brasileira, Carolina Maria de Jesus, Diário, Autobiografia, Memória. 


\section{Resumen}

En este texto analizamos el libro Quarto de despejo: diário de uma favelada (2015), publicado en los años sesentas, por la entonces desconocida Carolina Maria de Jesus. Escrito bajo el formato de diario, Carolina retrata la visión interna de una nueva realidad que consternaría la población brasileña hasta los días actuales: la chabola.

En sus escritos la escritora conllevó una serie de estigmas que señalaron peyorativamente su registro: era mujer, negra, pobre y semianalfabeta. Por ello sus obras dividen opiniones acerca de su valor literario. Este artículo objetiva analizar su primer libro, evocando aspectos autobiográficos y memoriales con relación a su tiempo y espacio.

Palabras clave: literatura brasileña, Carolina Maria de Jesus, Diario, Autobiografía, Memoria.

\section{Abstract}

In this text we analyze the book Quarto de despejo: diário de uma favelada (2015), published in the sixties by the then unknown Carolina Maria de Jesus. Written as a diary, Carolina portrays the inner vision of a new reality that would dismay the Brazilian population until the present day: la chabola [the shack]. In her pieces Carolina carried a series of stigmata that notoriously marked her writing since she was a woman, a black woman, a poor woman, and a half-literate woman. That is why his works divide opinions about its literary value. This article aims to analyze her first book, evoking autobiographical and memorial aspects in relation to his time and space.

Keywords: Brazilian Literature, Carolina Maria de Jesus, Diary, Autobiography, Memory.

\section{Introdução}

O objeto de estudo deste trabalho é protagonizado por Carolina Maria de Jesus, escritora nascida em Minas Gerais, em 1914, que se mudou para a cidade de São Paulo, em meados dos anos quarenta; presenciou e fez parte da formação das primeiras favelas do Estado e teve seu talento revelado em uma delas, na favela do Canindé. Foram necessários 56 anos para que $\mathrm{Ca}$ rolina, a mulher negra, favelada, mãe solteira e, ironicamente, semianalfabeta, conseguisse adentrar na seleta lista de escritores de literatura brasileira, com o reconhecimento da importância de seu primeiro livro, Quarto de despejo, publicado em 1960. Não há como negar que sua escrita plural, tão representativa de uma série de minorias, deva ser levada a sério. 
A percepção apurada de Carolina fez com que, embora ela estivesse em uma situação de extrema pobreza, sua voz ganhasse o poder de ser a interlocutora e mediadora de uma classe que permanece silenciada até os dias atuais. A sua narrativa de testemunho insere um novo discurso ao meio literário, em uma época em que o preconceito e a censura estavam em evidência devido às tensões decorrentes da Ditadura Militar. A sua fala-o grito da outra margem da sociedade-foi confrontada, discriminada e ignorada por muitos; porém, também foi ouvida por pessoas de várias classes, como afirma Robert Levine (1994: p. 49):

Para os estrangeiros, mais do que qualquer coisa, o Quarto e os demais livros de Carolina desmascararam o mito da democracia racial brasileira e que até então não havia sido mexido. Foi, paradoxalmente, uma mulher negra, da favela, que expôs as contradições entre a percepção cultural da elite e da realidade dos pobres. Mas aos olhos brasileiros era difícil reconhecer essas evidências através de Carolina, até porque ela própria reforçava em certas passagens o preconceito racial. A crítica discutiu a obra de Carolina em termos bem claros e evidentes para qualquer análise de discurso. Ela foi mostrada nos anos JK como sendo uma favelada preta, mulher pobre e de cor, vítima da miséria. Os acadêmicos falavam de sua produção como das classes subalternas escritas dos grupos oprimidos, subliteratura. No governo do sucessor de Juscelino, a linguagem ficou ainda mais feroz: para os conservadores, os favelados tornavam-se um caso de polícia; para a esquerda eles se constituíam em massa muda e emblemática, carente de doutrinação ideológica capaz de atuar de forma decisiva na ordem capitalista.

Como explicita Levine, o livro Quarto de despejo refletia a imagem das injustiças sociais cometidas no Brasil, no governo de JK.12 Além disso, provocou uma ruptura no fazer literário brasileiro, na percepção social e acadêmica. A resistência de um eu feminino reage contra os setores dominantes e sagra-se em uma luta interna, onde a fome e o estigma de ser favelada revelam-se cruéis. A Cinderela negra adentrou em distintas camadas sociais contando a história de sua vida, e mexeu com as bases da tradição literária, rompendo-a, conforme expressa Lejeune (2008: p.113):

12 O Governo Juscelino Kubitschek é o período de governo vivido entre 1956 e 1961. Sua eleição foi marcada pelo plano de ação "cinquenta anos em cinco", já que o ideal era trazer ao Brasil o desenvolvimento econômico e social em um período curto de tempo. 
Escrever e publicar a narrativa da própria vida foi por muito tempo, e ainda continua sendo, em grande medida, um privilégio reservado aos membros das classes dominantes. $\mathrm{O}$ "silencio" das outras classes parece totalmente natural: a autobiografia não faz parte da cultura dos pobres.

Carolina desejou ser dona da própria história e o foi. Seu diário, assim como toda obra autobiográfica, revela e evidencia uma multiplicidade situacional do pacto autobiográfico, proposto pelo autor francês Philippe Lejeune. São aspectos plurais de autor/narrador/ personagem e suas relações com a escrita. Texto e extratexto encontram-se, imagens do real e identidades cruzam-se e a obra é preenchida de uma afirmação inquestionável, de um "eu" que honra a sua assinatura e o seu discurso. A produção de Carolina carrega consigo essa responsabilidade (pacto) e ecoa por várias gerações que se identificam com seus pensamentos.

\section{A escrita pluralista de Carolina}

Em sua obra Quarto de despejo (2015), Carolina Maria de Jesus apresenta uma mescla de subgêneros, representações biográficas e autobiográficas que compõem um gênero principal, que é o próprio diário. Lejeune entende esse processo como sendo um vestígio: quase sempre uma escrita manuscrita, pela própria pessoa, com tudo o que a grafia tem de individualizante. [...] Ele pressupõe a intenção de balizar o tempo através de uma sequência de referências. $O$ vestígio único terá uma função diferente: não a de acompanhar o fluxo do tempo, mas a de fixá-lo em um momento-origem (Lejeune, 2008: p. 260).

Para Carolina, o seu "estranho" diário é uma criação artística e ao mesmo tempo uma imersão em sua própria vida, não podendo haver dissociações entre ambas. Elas estão ligadas através de um fio condutor que é a escrita. Seu produto é fruto da reflexão e expressa sua visão por meio da representação da realidade. A inexistência de distanciamento entre a mulher Carolina e a escritora permite que sua voz não termine ao iniciar o seu trabalho criativo. Germana Sousa (2012: p. 147) afirma que:

O estudo da obra de Carolina exige que se leve em conta os determinantes biográficos que estão em sua origem. Tampouco é possível pautar o estudo apenas por eles, um risco sempre presente no horizonte da crítica. É preciso, pois, não negligenciar nenhum dos dois lados da questão. O diário de Carolina abre o espaço para o crítico estudar e compreender 
a sua obra por meio da autorreflexão que a autora faz dentro dele. Sendo também uma criação estética, o cotidiano da autora, sua condição social, é fator determinante da construção literária. Daí a autora referir-se ao texto como sendo estranho.

Vê-se que, para Carolina, além de sua importância no âmbito pessoal, seu diário adquire outra proporção, ele a projeta no mercado literário e faz com que seus escritos íntimos se revelem como testemunhos de uma realidade desconhecida para a sociedade brasileira e mundial: a favela e seus habitantes.

Dessa maneira, por mais críticas que esse gênero possa sofrer, sua importância como ponto observatório é riquíssimo. Carolina teve como espelho grandes nomes do cânone literário, personalidades como: Sartre, Virginia Woolf, Florbela Espanca e Barthes. Todos eles responsáveis pelo resgate "de uma história social que foi expurgada dos manuais da história oficial e por essa razão podem fazer girar a lente do observador da história" (Sousa, 2012: p. 172).

E assim Carolina o fez, deu voz aos esquecidos pela sociedade, aos marginalizados e seus silêncios. A experiência que a autora entregava ao público era algo novo, em um contexto literário controlado pela classe dominante, alguém que advém de uma classe distin- ta consegue espaço. A sua história não seria contada por outro, mas por ela mesma. Não seria o morador da casa de alvenaria o detentor da palavra e sim a própria dona do barracão.

Do discurso de Carolina depreende-se que ela tinha um senso político aguçado, corroborado por meio do título do livro que reforça a ideia de que "a favela é o quarto de despejo. E as autoridades ignoram que tem o quarto de despejo" (Jesus, 2015: p. 107). Metaforicamente, a autora sugere que, assim como na casa, o governo também tem um lugar onde "depositar" o que não se quer ou que se despreza; nesse caso, o espaço é a favela.

O texto, narrado em primeira pessoa, possibilita a inserção dos subgêneros supracitados anteriormente ao gênero principal. $O$ narrador e o autor formam um ser único, constatação apresentada também por Germana Sousa (2012: p. 176):

A escolha do tipo de focalização traz implicações determinantes para a leitura da obra, pois define o nível de implicação (compromisso/descompromisso, consonância/dissonância, piedade/ironia) que o narrador tem com relação àquilo que narra, o mundo diegético. $\mathrm{Na}$ verdade, a focalização trata não apenas da visão do personagem, mas das relações en- 
tre o que diz o narrador e o que sabe o personagem.

No entanto, Quarto de despejo requer uma atenção especial do leitor, pois, ainda que o livro seja autêntico e pertencente ao gênero não-ficcional, ele foi editado e compilado por outra pessoa, o "descobridor" de Carolina, o jornalista Audálio Dantas, que realiza o prefácio da obra e explica como ela veio à luz. Essa constatação não será levada em consideração neste trabalho, já que a escrita contida no livro expressa o cotidiano real somente da autora, não havendo relação direta com o seu editor. Reitera-se aqui que Carolina é a dona das palavras que ela produz.

Essa autoria evidenciada na primeira pessoa permite que se tenha mais segurança na relação igualitária entre ficção e realidade. Esse composto binário é sustentável pela experiência do autor e do autoconhecimento, fato que o afasta da ficção ou da representação. Já em relação ao leitor da autobiografia, Lejeune interpreta que ele

vive sua relação com o texto de dois modos simultâneos: sensível a voz narrativa (eu), tem a impressão de estar em situação de comunicação com o autor-narrador, integrando à imagem que dele faz tudo aquilo que sua enunciação (do autor-narrador) revela. Porém, ao mesmo tempo, guiado pelo relato, reconstrói o modelo biográfico que lhe é sugerido (Lejeune, 1980: p.61). [Tradução livre nossa] ${ }^{13}$

Devido a esse terreno tão dúbio, os estudos sobre o gênero autobiográfico revelam uma problemática em relação à aceitação desse gênero por parte da academia. A ambiguidade de seu produto faz com que grande parte das críticas literárias e historiográficas rechace esse estilo. O flerte com a realidade e a ficção simultaneamente dá margem à imprecisão quanto a sua classificação, pois não há aprofundamento em nenhum dos polos.

Em seu livro Je est un autre, Lejeune indaga sobre a questão do hibridismo autoral da autobiografia e se dá conta de que “a questão 'quem fala?' não remete apenas aos meandros da personalidade, mas também aos 'autores' múltiplos de um mesmo 'eu', ao mesmo tempo em que remete ao jogo social pelo qual os 'sujeitos' se reproduzem" (Lejeune,

13 No original: "Celui-ci vit sa relation au texte sur deux plans à la fois: sensible à la voix narrative, il a l'impression d'être en situation de communication avec l'auteur-narrateur et l'integre à 1 'image qu'il se fait de lui tout ce qui révèle son énonciation. Main en même temps, guidé par le récit, il reconstruit le modèle biographique qu'on lui suggère" (Lejeune, 1980:p.61). 
1980: p. 8) [Tradução livre nossa) ${ }^{14}$.

Desse modo, no diário de Carolina temos essa soma de "eus": o eu autor, o eu narrador, o eu personagem e o eu real, confirmando, mais uma vez, que o gênero diário pertence ao gênero autobiografia. Essa ligação textual e extratextual é aferida quando o leitor toma consciência da história de vida de Carolina, aceitando-a como verídica. $\mathrm{O}$ contrato do pacto autobiográfico, segundo Germana Sousa (2012: p. 159), é “concretizado pelo título que evidencia, pela referência ao gênero (diário, autobiografia, memórias, confissões) que o texto tem em relação com a vida do autor".

A partir do subtítulo do livro, Diário de uma favelada, várias informações são passadas aos leitores como: tratar-se de uma favelada e o gênero da obra, diário; revelações que se confirmam quando o leitor as relaciona ao histórico de vida da autora. Porém, existe outro pacto que é passível de falsidade: o pacto referencial. Como saber se o que foi escrito por Carolina é verdade? Por mais que a autora utilize nomes e endereços que atestam veracidade aos fatos, certas opiniões manifestadas são de caráter pes-

14 No original: "La question 'Qui parle?' ne renvoie plus seulement aux méandres de la personnalité, mais aux 'auteurs' multiples d'un même 'jê', en même temps qu'au jeu social par lequel les 'sujets' se reproduisent" (Lejeune, 1980: p. 8). soal, não representando uma verdade absoluta. Para Lejeune (2008: p. 37):

$\mathrm{Na}$ autobiografia, é indispensável que o pacto referencial seja firmado e que ele seja cumprido: mas não é necessário que o resultado seja da ordem da estrita semelhança. $\mathrm{O}$ pacto referencial pode ser, segundo os critérios do leitor, mal cumprido, sem que o valor referencial do texto desapareça (ao contrário) o que não é o caso nas narrativas históricas ou jornalísticas (grifos do autor).

Interpretando o exposto, ainda que certas afirmações de Carolina possam não ser totalmente fiéis à realidade, elas são justificadas pelo que o gênero diário implica. Germana Sousa (2012: p. 165) sustenta que "o diário é um gênero íntimo que, contrariamente à autobiografia, não fixa o 'eu' e não busca a compreensão da totalidade de si mesmo, devido à sua temporalidade, que é a do fragmento e do presente". Apesar de ser um gênero sólido, a fragmentação de pensamentos e o "congelamento" dos momentos não abrangem a totalidade do "eu", da verdade ou das mudanças de pensamentos ocorridas após a escrita. No diário, tudo é reflexo do momento.

Após essas observações, compreendemos que, nesse emaranhado de gêneros que se configura o Quarto de despejo, o 
pacto referencial toma uma dimensão ínfima e não compromete o resultado do texto, pois tudo o que é descrito é justificável pelo hibridismo de suas categorias. $\mathrm{O}$ pacto autobiográfico permanece intacto, dando legitimidade ao diário de Carolina.

\section{Carolina e os enfrentamentos do "eu"}

Após a constatação do hibridismo de gêneros e a confirmação do pacto autobiográfico proposto por Phillipe Lejeune, propomos trilhar os caminhos enveredados por Carolina Maria de Jesus e investigar os enfrentamentos, o cotidiano e sua atuação como escritora. Nesse sentido, trataremos de três temas que permeiam a sua obra: o machismo, a fome e o racismo.

Os estudos contemporâneos a respeito das narrativas de autoria feminina revelam uma marginalização dessa escrita e um ocultamento dessas manifestações literárias. A sociedade assimilou a ideologia machista e patriarcal que afirma que as mulheres não escreviam por falta de talento, uma taxação misógina, e que foi amplamente discutida pela escritora inglesa Virginia Woolf, em um dos seus mais icônicos ensaios chamado Um teto todo seu, publicado em 1929. Woolf afirmou, com veemência, que "uma mulher precisa ter dinheiro e um teto todo seu, um espaço próprio, se quiser escrever ficção" (Woolf, 2014: p.12), uma independência de que poucas mulheres gozavam.

Levando em conta tal afirmativa, ao analisar a obra de Carolina, sejam aspectos biográficos ou literários, nota-se uma independência em relação à subordinação masculina e suas implicações. A escritora possui um teto todo dela, o barracão, e é nesse ambiente, hostil e vicioso, que sua literatura é construída:

Eu deixei o leito as 3 da manhã porque quando a gente perde o sono começa a pensar nas miserias que nos rodeia (...) Deixei o leito para escrever. Enquanto escrevo vou pensando que resido num castelo cor de ouro que reluz na luz do sol. Que as janelas são de prata e as luzes de brilhantes. Que a minha vista circula no jardim e eu contemplo as flores de todas as qualidades. (...) É preciso criar este ambiente de fantasia, para esquecer que estou na favela (Jesus, 2015: p. 58) $)^{15}$.

A situação marginal de Carolina conferiu ao seu discurso um caráter de denúncia,

15 A obra de Carolina Maria de Jesus apresenta uma série de imprecisões ortográficas, fruto de sua pouca escolaridade, que foi mantida porque esse é o seu registro. Também se observa algumas omissões em forma de reticências, fruto do tratamento que Audálio Dantas deu ao original, para evitar repetições, tão comuns à linguagem oral.
56 O diário de Carolina Maria de Jesus. Uma brasileira marginalizada Regina Simon da Silva

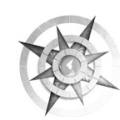


revelando não somente a sua expressividade literária, como também um viés político e social de uma classe periférica. A sua escrita, de tom realista, rompeu com a tradição literária e chamou a atenção de um público que se encontrava alheio a essa realidade, feito impensável de ser alcançado pelo discurso oral, comum nas comunidades pobres onde poucos são os que leem ou escrevem.

As adversidades enfrentadas por Carolina eram muitas, mas a que ela mais enfatizou em seus escritos refere-se àquela provocada pela fome. Em diversos momentos, a autora narra as batalhas diárias para conseguir comida para si e para os seus filhos. A fome, em um lugar de extrema pobreza, surge como a pior inimiga, fato que lhe causava muita revolta, principalmente porque ela tinha consciência da injustiça que reinava no Brasil de sua época. Em um de seus relatos mais fortes, é possível conhecer a dolorosa vida de Carolina e de outros favelados:

[...] Os lixeiros haviam jogado carne no lixo. E ele escolhia uns pedaços. Disse-me:

Leva, Carolina. Dá para comer.

Deu-me uns pedaços. Para não maguá-lo aceitei. Procurei convencê-lo a não comer aquela carne. Para comer os pães duros ruídos pelos ratos. Ele disse-me que não. Que há dois dias não comia. Acendeu o fogo e assou a carne. A fome era tanta que ele não poude deixar assar a carne. Esquentou-a e comeu. Para não presenciar aquele quadro, saí pensando: faz de conta que eu não presenciei esta cena. Isto não pode ser real num paiz fértil igual ao meu. Revoltei contra o tal Serviço Social que diz ter sido criado para reajustar os desajustados, mas não toma conhecimento da existencia infausta dos marginais. Vendi os ferros no Zinho e voltei para o quintal de São Paulo, a favela.

No outro dia encontraram o pretinho morto. [...] Não trazia documentos. Foi sepultado como um Zé qualquer. Ninguém procurou saber seu nome. Marginal não tem nome.

... De quatro em quatro anos muda-se os políticos e não soluciona a fome, que tem sua matriz nas favelas [...] (Jesus, 2015: p. 40).

São inúmeras as passagens de Quarto de Despejo que escancaram a realidade da desigualdade social daquele Brasil - e por que não o de hoje -, descrições que ganharam repercussão imediata entre os brasileiros, haja vista o sucesso do livro. Em seguida, com a publicação da obra em vários países europeus, uma parte ignorada do país foi revelada e a originalidade da obra de Carolina reconhecida. 
Esse fato histórico, tão importante para a literatura brasileira, pouco é lembrado por nossa sociedade.

O preconceito que permeia a vida de Carolina também invade a sua obra, caracterizado em um dos temas mais recorrentes em seu livro, o racismo. Quarto de Despejo retrata as feridas desse assunto ainda tão presente no cotidiano social: "Enquanto eu estava na rua o Alexandre maltratou a mãe do soldado Edison. Quando eu cheguei ele começou insultar-me: [ Negra suja. Ordinária. Vagabunda. Lixeira" (Jesus, 2015: p. 98), ofensas que expõem o forte preconceito racial em nosso país.

O livro apresenta um diagnóstico preciso da dominação racial que impera em nossa sociedade. Vale salientar que Carolina não teve uma educação de qualidade, assim como tantos outros de sua mesma esfera. Desse modo, nota-se a assimilação de um discurso social amplamente propagado, sentido nas inúmeras vezes em que Carolina é preconceituosa consigo mesma, quando afirma que não gostava de preto. Segundo Joel Rufino dos Santos (2009: p. 133) “o preconceito racial existe entre os pobres e pretos porque o racismo é sistêmico". Em um diálogo com uma senhora que comprava em um mercado, podemos observar esse discurso contraditório:
[...] Uma senhora que fez compra gastou 43 cruzeiros. E o senhor Eduardo disse:

- Nos gastos quase que vocês empataram.

Eu disse:

- Ela é branca. Tem direito de gastar mais.

Ela disse-me:

- A cor não influi.

Então começamos a falar sobre o preconceito. Ela disse-me que nos Estados Unidos eles não querem negros na escola.

Fico pensando: os norte-americanos são considerados os mais civilisados do mundo e ainda não convenceram que preterir o preto é o mesmo que preterir o sol. O homem não pode lutar com os produtos da Natureza. Deus criou todas as raças na mesma epoca. Se criasse os negros depois dos brancos, aí os brancos podia revoltar-se (Jesus, 2015: p. 122).

Essa passagem ilustra bem a contradição a que nos referimos. Carolina repete o mesmo discurso da dominação branca do qual é vítima quando afirma que eles podem gastar mais, simplesmente pelo fato de serem brancos. Porém, diante da resposta de sua interlocutora, Carolina reflete acerca da questão da desigualdade social e parece perceber sua incoerência. 
A obra de Carolina ganha importância ao retratar a condição subalterna dos negros no Brasil, desde os tempos coloniais. O desenvolvimento do país não apagou seu passado, que segue contaminando as novas gerações que repetem as mesmas práticas, nas estrelinhas de seus discursos e ações cotidianas, dificilmente identificadas e punidas.

Destacamos, assim, alguns momentos do diário que comprovam o delicado limiar das questões raciais vividas por Carolina. Analisando-os, percebemos que a imposição social opera sua prática a partir da cor do indivíduo:

[...] Fui na casa de uma preta levar umas latas que ela havia pedido. Latas grandes para plantar flores. Fiquei conhecendo uma pretinha muito limpinha que falava muito bem. Disse ser costureira, mas que não gostava da profissão. E que admirava-me. Catar papel e cantar (Jesus, 2015: p. 25).

Nesse fragmento, vemos que o que chama a atenção de Carolina é o fato de reconhecer entre os moradores da favela uma mulher negra que foge à regra: é limpinha e fala bem, características pouco comuns à sua raça; causa estranheza pela exceção.
Em um segundo momento, Carolina retrata o óbvio em uma sociedade onde impera a desigualdade social. Essa memória foi registrada em 13 de maio ${ }^{16}$, um dia especial para ela: “...Nas prisões os negros eram os bodes expiatórios. Mas os brancos agora são mais cultos. E não nos trata com despreso. Que Deus ilumine os brancos para que os pretos sejam feliz" (Jesus, 2015: p. 30). O agradecimento dispensado aos brancos mostra a hierarquização e a dependência que os negros mantêm em relação a aqueles. Pedir a bênção em nome alheio para ser tratado de maneira digna demonstra submissão e humilhação em relação ao outro. Carolina, dessa forma, autodenomina-se subordinada e vítima da desigualdade social.

No fragmento seguinte, depreende-se, por meio da conotação da cor negra, certo pessimismo, uma acomodação em relação à posição do negro na sociedade:

Antigamente era a macarronada o prato mais caro. Agora é o arroz e feijão que suplanta a macarronada. São os novos ricos. Passou para o lado dos fidalgos. Até vocês, feijão e arroz, nos abandona! Vocês que eram os amigos dos marginais, dos favelados, dos indigentes. Vejam só.

16 Dia simbólico em que se comemora a abolição dos escravos no Brasil. 
Até o feijão nos esqueceu. Não está ao alcance dos infelizes que estão no quarto de despejo. Quem não nos despresou foi o fubá. Mas as crianças não gostam de fubá. Quando puis a comida o João Sorriu. Comeram e não aludiram a cor negra do feijão. Porque negra é a nossa vida. Negro é tudo que nos rodeia (Jesus, 2015: p. 43).

O humor presente no texto não esconde a crítica da autora em relação ao empobrecimento da população e a luta diária pela sobrevivência. A palavra "negro" alude a tudo o que é negativo, sujo, perigoso.

Já na próxima citação, Carolina expressa um juízo de valor errôneo, como se os atributos fossem meramente categorizados por meio da raça: "A Florenciana é preta. Mas é tão diferente dos pretos por ser ambiciosa. Tudo que ela faz é visando lucro. Creio que se ela fosse dona de um matadouro havia de comer os chifres e os cascos dos bois" (Jesus, 2015: p. 75). Seguindo seu raciocínio, um negro nunca poderia ser ambicioso, pois não faz parte de sua natureza. Uma frase que remete ao processo de colonização que impede que um negro ascenda socialmente, discurso assimilado e sempre repetido por Carolina em várias partes de sua obra.
A análise de temas tão significativos requer um aprofundamento bem maior do que o proposto neste artigo acadêmico. Sabe-se que são temas complexos, que demandam um espaço bem maior de conteúdo e pesquisa. Assim, espera-se que esse breve olhar acerca desses três tópicos norteadores da obra de Carolina sirva como um ponto de partida para um olhar mais crítico e intrínseco de um leitor/pesquisador interessado em questões tão pertinentes para o entendimento da construção da imagem de um Brasil que é refletido em obras literárias como essa.

Para finalizar, Quarto de despejo reforça o pressuposto de que a Literatura é algo atemporal. Não pode e não deve ser vista apenas como mero objeto estético, sem levar em conta o contexto histórico e os valores ideológicos socioculturais presentes em uma esfera externa, mas que possui livre acesso ao universo literário.

Carolina Maria de Jesus criou um poderoso instrumento de transformação social, rompeu barreiras civis e literárias e deu ao mundo uma lição de sobrevivência, expondo uma visão interna da favela e de como era sua vida e linguagem. Seu feito, mesmo estando fora dos padrões literários do cânone, tem força e representatividade, ao caracterizar 
uma nação que esconde seus males à margem, em um quarto de despejo.

A obra de Carolina transita livremente, desde a sua composição sem amarras, por onde passeia entre os mais diversos gêneros literários (autobiografia, diário, memórias) ou pelo tempo, onde nos deparamos com temas de extrema contemporaneidade, vistos e debatidos como: os feminismos, as desigualdades sociais e a questão dos preconceitos.

Entrar em contato com essa narradora-testemunha é confrontar experiências sociais e literárias. Este artigo serve como meio sensorial, no que tange ao vivenciar o outro. Que esta produção sirva como resgate aos escritos de Carolina Maria de Jesus e mostre que a Literatura não pode ser vista só como um mecanismo puramente acadêmico, mas como uma arma capaz de transformar o homem, elevando-o ao grau máximo de sua serventia, e de melhorar a si mesmo.

\section{Referencias bibliográficas}

Jesus, C. M. (2015): Quarto de despejo: diário de uma favelada. São Paulo: Ática.

Lejeune, P. (1980). Je est un autre: L'autobiographie, de la littérature aux médias. Paris: Seuil.

Lejeune, P. (2008): O pacto autobiográfico: de Rousseau à Internet. Belo Horizonte: UFMG.

Levine, R. (1994):Uma história para Carolina. En: Meiry, J. C. S. B.; Levine, R. M. (Orgs.). Cinderela Negra: a saga de Carolina Maria de Jesus. Rio de Janeiro: UFRJ.

Santos, J. R. (2009). Carolina Maria de Jesus: uma escritora improvável. Rio de Janeiro: Garamond.

Sousa, G. (2012): Carolina Maria de Jesus: o estranho diário da escritora vira lata. Vinhedo: Horizonte. 